\title{
Children's memory for counting-out rhymes: A cross-language comparison
}

\author{
DAVID C. RUBIN \\ Duke University, Durham, North Carolina \\ VIOLETA CIOBANU \\ Bucharest University, Bucharest, Romania \\ and \\ WILLIAM LANGSTON \\ Denison University, Granville, Ohio
}

\begin{abstract}
In English, counting-out rhymes, such as "Eenie Meenie," vary little over retellings. Recall is not rote but is sensitive to the structure of the genre. To test the generality of this finding, a sample of Romanian rhymes was collected. Although there was no overlap with the English rhymes, the corpus of rhymes collected had similar structure in terms of number of lines, repeating words, rhyme, alliteration, and the inclusion of nonsense words. Variation within rhymes preserved the poetic structure of the genre. The results suggest that verbatim recall can be schema driven if there is sufficient structure.
\end{abstract}

Counting-out rhymes, such as "Eenie, Meenie," are used by children to determine who gets to do an unpleasant job. Performances must be verbatim; changes in wording can lead to a different person being chosen. The children who use these rhymes are sensitive to this need, and because they are often preliterate, they need to rely on their memories to produce verbatim recall.

How is this verbatim recall maintained? An analysis of English language counting-out rhymes demonstrates that verbatim recall is not obtained by rote memorization (Rubin, 1995). Rather, verbatim recall is obtained by following the rules of a genre that has multiple constraints; that is, by schema-driven recall in which the schema includes rhythmic and poetic structure as well as meaning. Because counting-out rhymes are defined in terms of their use, no regularities in form are part of their definition, and so any such regularities noted are empirical findings that can be used to determine the structure of the schema and infer the memory mechanisms being used.

Consider the counting-out rhyme that has been the most common in the United States, and possibly the Englishspeaking world, for the last century: "Eenie, meenie, miney, mo./Catch a tiger by the toe./If he hollers, let him go./Eenie, meenie, miney, mo." The poetics are subtle and exhaustive. Most of the words contain a repeated sound pattern, usually word repetition, rhyme, or alliteration, and all the words not involved in the meaning are involved in one

We wish to thank Valentin and Ioana Dragoi for their help with the poetics, Viorica Marian for her comments, and the McDonnell Foundation Program for the Advancement of Psychology in Romania for partial support for the research. Correspondence should be addressed to D. C. Rubin, Experimental Psychology, Duke University, Durham, NC 27708-0086 (e-mail: rubin@psych.duke.edu). of these poetic devices. Consider the first line, which has remained stable without any deep structure. The first word, eenie, is part of the second word, meenie (Jakobson, 1960). Meenie, miney, and mo alliterate. Eenie, meenie, and miney rhyme with a sound that repeats as the first vowel of eenie and meenie. Mo rhymes with toe and go. The first line also contains a progression of front-to-back middle vowels- $e$, $i, o$-as in the fee, fi,fo of fee, fi,fo, fum, or in the ee eye, $e e$, eye, oh of "Old McDonald had a Farm." Therefore meenie, miney, mo sounds better than miney, meenie, mo, and the order is unlikely to change. The remaining sound, $/ \mathrm{n} /$, repeats in the same location in three words. The whole line repeats as the last line, where the one single syllable word, mo, coincides with the person who is chosen. This change from the two syllable pattern adds to the closure of the piece (Herrnstein Smith, 1968). This change at the end of the line, and other lines, from a trochaic (i.e., stressed unstressed or '-) foot to a single stressed syllable emphasizes the end-rhyme scheme by putting a stress on the final rhyming syllable (i.e., ' $-{ }^{\prime}-{ }^{\prime}$ vs. ' $-{ }^{-}-{ }^{\prime}-$ ). Thus, there is not a phoneme or even a distinctive feature in the first line that can change without breaking some pattern. The middle two lines offer more flexibility and do change more over time and over retellings (Rubin, 1995). A similar combination of multiple constraints also holds for the second most popular rhyme: "One potato, two potato/Three potato, four./Five potato, six potato/Seven potato, more," with the word potato kept singular to preserve rhyme and repetition. For this rhyme, however, there is a stronger meaning constraint in the form of counting, which accounts for all words except the repeating word potato and the rhyming word more.

For at least these two rhymes, there exists the structure to support the claim that multiple constraints combine to 
limit choices and cue memory once the rhyme is begun (Rubin \& Wallace, 1989). Evidence for the use of these constraints comes from variability in retellings of the rhymes over generations, across locations, and within the same person (Rubin, 1995). Changes occur within the rhymes in a way that preserves the rhyme or in places where they do not violate the constraints. For instance, on repeated telling the unstressed and unconstrained word the in "Eenie Meenie" changes to his or its.

The most dramatic change is in "Eenie Meenie"; social currents in the 1940s forced what was caught by the toe to be changed. A host of two-syllable animate nouns were tried (e.g., doggie and piggy, but not dog or pig), many probably suggested by adults, but the consensus of the young practitioners of this tradition settled on the two-syllable word, tiger, which alliterates with toe. The runner-up was monkey, which alliterates with three of the four words in the first line. It is hard to find better poetic solutions. Thus sensitivity to the constraints was shown.

The multiple constraint account of stability in memory, though consistent with that given for other oral traditions (Rubin, 1995), is based on the examination of the same corpus that it explains. To test it, a new corpus is needed-one in a language similar enough to English to have at least some similar properties, but not one in which extensive borrowing has occurred. Romanian provides an ideal test. Romanian shares the romantic language roots of English. Its speakers are surrounded linguistically by Hungarian, Slavic, and nearby Turkish languages, isolating them from easy borrowing from other Romance languages or English. An examination of the corpus of counting-out rhymes shows no overlap with English rhymes (Abrahams \& Rankin, 1980). The Romanian rhymes also appear not to overlap with the rhymes of their linguistic neighbor, Italian.

\section{METHOD}

\section{Subjects}

A total of 159 children ( 71 males) between the ages of 6 and 11 (mean age of 8.14 years) from the Bucharest area were tested.

\section{Procedure}

The subjects were tested individually in a quiet room. A native speaker of Romanian asked them to produce rhymes of the kind they would use to choose someone in a game. The first line of one rhyme, Din oceanul Pacific, was used as an example. Nondirective encouragement to recall more rhymes and to complete ones started was given.

\section{RESULTS}

A total of 284 counting-out rhymes were collected, or 1.78 rhymes per child (range $=1-4$ per child). There were 26 unique rhymes. The most popular 18 of these rhymes occurred $63,40,35,25,21,19,14,10,9,8,8,7,4,4,3$, 2,2 , and 2 times each. The remaining 8 rhymes were each collected once. Thus, as is common with many frequency distributions, usage is highly skewed; the medianfrequency rhyme occurs only four times, and the most popular five rhymes account for $65 \%$ of all occurrences.
The five most common rhymes are examined in detail because they account for most of the corpus and because they occurred frequently enough to provide an opportunity to study variation within each rhyme. Following this, the set of modal versions of each of the 26 rhymes is examined to determine the general properties of the genre and to look for differences between the common and rare rhymes. To do this, the 12 rhymes that were reported seven or more times were compared to the 14 rhymes that were reported four or fewer times. The transcription of the Romanian speaker who recorded the lines determined the number of lines per rhyme.

\section{Analysis of Variability in the \\ Five Most Common Rhymes}

The most common rhyme collected was the one whose first line was used as an example. Therefore both its frequency and the stability of the first line may be exaggerated. Its most common variant occurred 49 times: "Din oceanul pacific/A ieşit un pește mic/Şi pe coada lui scria/ Ieşi afară dumneata" (From the Pacific ocean/A little fish came out/And on his tail was written/Out goes you). Another 12 versions were identical except that the last line was replaced by "Te iubesc, nu mă uita" (I love you, don't forget me). This variant was used exclusively by girls. One variant replaced the last two lines by "Iu, iu, iu/Ieşi afară tu" (Iu, iu, iu/Out goes you), and another by "A b c/leşi afară dumneata" ( $\mathrm{A} \mathrm{b} \mathrm{c/Out} \mathrm{goes} \mathrm{you).} \mathrm{Thus} \mathrm{the} 63$ occurrences from 63 different children are quite similar: 49 are identical, 12 more are identical to each other and occur as part of a gender-specific variant, and the 2 nonce variants substituted lines that are common in other rhymes in the genre.

The second most frequent rhyme is, "Pe o bară/Se căca o cioară/Ga, ga, ga/Drept în gura ta" (On a bar/A crow was defecating/Ga, ga, ga/Right in your mouth). This variant has 26 occurrences. An additional 11 occurrences use "Cra, cra, cra" and one uses "Gra, gra, gra." One occurrence substitutes "Iu, iu, iu/Ieşi afară tu" for the last two lines, lines also seen in the previous rhyme. The final remaining occurrence uses "aşeza" (sitting) instead of "căca" in the second line. Again there is considerable stability: 38 of the 40 occurrences differ only in what the crow says, one other substitutes a common ending from other rhymes, and one changes one word.

The third most popular rhyme, which occurs 35 times, has 16 occurrences of "Stan şi Bran/Cântă la pian/Tu, tu, tu/Ieşi afară tu" (Stan and Bran [i.e., Laurel and Hardy]/ Play the piano/You, you, you/Out goes you). Another 16 occurrences substitute "Iu, iu, iu" for "Tu tu tu," and one occurrence substitutes "piu, piu, piu," neither of which has a translation. The only variation that does not occur by substituting another word for $t u$ in this line is the following substitute for the last two lines, which occurs twice: "Muzică uşoară/Ieşi afară domnişoară" (Pop music/out goes you, young lady).

Twenty-three of the 25 occurrences of the fourth most frequent rhyme consist of "An tan te/Di ze ma ne pe/Di 
ze ma ne compare/An tan te." The two remaining occurrences are the substitution of $d a n$ for the last occurrence of tan or for both occurrences. All words are nonsense in Romanian, although some borrowing from Italian is conceivable (andante, mane, compare).

The fifth rhyme has 21 occurrences, 17 of which begin with the same first four lines, after which the person who is counted on responds with a word, which is spelled out. This technique is also used in the United States (e.g., "My mother and your mother were hanging out clothes/My mother punched your mother in the nose/What color was the blood?/r e d"). It takes some of the power from the person who is counting and may be a way of minimizing cheating (Goldstein, 1971). The rhyme is "Pe capetele noastre/Trece un tramvai/În ce directie/Trece acest tramvai"/(Spell one of the following choices) "B u c u r e ş t i" [four times], "B e r l i n" [once], "C ol e n t in a" [once], "G e r m a n i a" [once], "S i b i u" [once], [no mention of a location, nine times]. Over our heads/Goes a tramway/In what direction/Goes this tramway?). The remaining four occurrences all change the first word of the third line to din and the first word of the last line to vine. This changes the meaning of the last two lines to "from what direction/comes this tramway?"

Overall, for an oral tradition kept in the memory of 8 -year-old children, the stability is remarkable. The changes that do occur are few and fit within the structure of the rhyme. These variations could be viewed as local variations, but even if they are viewed completely as errors in recall, the recall is quite accurate, not at all like the recall in the rumor studies of Allport and Postman (1947) or the serial reproduction studies of Bartlett (1932).

\section{Properties of the 26 Rhymes}

In all analyses that follow, the corpus is analyzed on a per-rhyme basis. Thus, when overall measures are given, properties of words and lines are first averaged for each rhyme, providing a value for each rhyme that is used in statistical analyses. When a large corpus of English countingout rhymes (Abrahams \& Rankin, 1980) was divided into the 24 most common rhymes and 24 rhymes collected only once, few differences were noted, and those differences were subtle: The common counting-out rhymes had more four-beat lines, better poetics as rated by adults, and more of their poetically linked words falling on stressed syllables (Rubin, 1995). Moreover, the stress pattern followed many of the rules of formal English poetry (Kelly \& Rubin, 1988). These commonalties argued for a single genre, or schema, for counting-out rhymes that extended even to rhymes that were not widely used. To provide a similar analysis, the sample of 26 Romanian rhymes was split into the 12 rhymes collected seven or more times and the 14 less common rhymes collected four or fewer times.

English counting-out rhymes tend to have four lines with four beats to the line. This appears to be a widespread pattern in children's rhymes, especially if a musical rest is allowed to be transcribed for a beat (Burling, 1966). Ten of the 12 most frequent Romanian rhymes and 7 of the 14 less common rhymes had four lines. In terms of averages, there were 4.88 lines per rhyme $(S D=1.84 ; 4.58$ for the more common rhymes, $S D=1.50 ; 5.14$ for the less common rhymes, $S D=2.11$ ). Thus the Romanian countingout rhymes tend to have four lines.

Rhyming among the last words of lines is common in English and Romanian rhymes. Here - and only in this measure-we count repeating words as rhyming words because of the strong expectation of a rhyme in the genre and because the limited number of locations (one per line) decreases the chances of a rhyming word being detected without it being intentional. Here and elsewhere, we set a weak criterion for rhyme, defining it as a match in the last vowel and everything beyond it. In English, 71\% of the lines rhymed. In Romanian, $86 \%$ of the lines rhymed $(S D=19 \%$; for the more common rhymes, $85 \%, S D=$ $22 \%$; for the less common rhymes, $87 \%, S D=17 \%$ ). All 26 rhymes had at least one pair of lines rhyming and 15 had all lines rhyming. The dominant mode of the rhyming is the couplet, with only one of the rhymes not having at least one adjacent pair of lines rhyming.

In the English rhymes, approximately $22 \%$ of the words are nonsense words (Rubin, 1995), in the Romanian rhymes, $15 \%$ are nonsense words $(S D=32 \%$; for the more common rhymes, $22 \%, S D=36 \%$; for the less common rhymes, $9 \%, S D=27 \%$ ). Such nonsense words, as seen in the English example of "Eenie Meenie," allow for increased phonetic structure at the expense of semantic structure. Among the 12 common Romanian rhymes, 1 was made entirely of nonsense words, 1 had one word that was not nonsense, and 3 had one line of nonsense. Two of these three rhymes repeated an animal sound three times as the nonsense line and one used the line "an tan tina." For the 14 less common rhymes, 1 was entirely nonsense and 1 had the line "an tan tina." The two common rhymes that were all or mostly nonsense both had a line beginning an tan. Thus, the an tan nonsense words seem to transfer from rhyme to rhyme in a productive formulaic fashion that alters some of the line to fit local constraints (Lord, 1960).

In the English rhymes, approximately $16 \%$ of the words repeat an earlier word (Rubin, 1995); in the Romanian rhymes, this rate is $12 \%(S D=11 \%$; for the more common rhymes, $15 \%, S D=13 \%$, with a range of 0-4 repetitions, except for one rhyme with seven repetitions; for the less common rhymes, $10 \%$ repeat, $S D=$ $10 \%$, with a range of $0-4$, except for one rhyme with 13 repetitions). These values and those that follow for rhyme and alliteration were calculated in a conservative way to avoid capitalizing on chance occurrences (Skinner, 1939, 1942). The first time a repeating word (or sound pattern such as rhyme or alliteration) occurred, it was not counted. Only the second and later occurrences were counted. Moreover, once a word was counted as a repetition, it could not be counted as a rhyme or alliteration (Rubin, 1995).

For the English rhymes, approximately $22 \%$ of the words rhyme with other words in the rhyme (Rubin, 1995). In the Romanian rhymes, that rate is $32 \%(S D=11 \%$; for the more common rhymes, $32 \%, S D=13 \%$; for the less common rhymes, $32 \%, S D=9 \%$ ). 
In the English rhymes, approximately $23 \%$ of the words alliterate with earlier words (Rubin, 1995). In the Romanian rhymes, $20 \%$ alliterate $(S D=14 \%$; for the more common rhymes, $13 \%, S D=11 \%$; for the less common rhymes, $26 \%, S D=13 \%$ ).

We can ask what percentage of the words are involved in repetition, rhyme, or alliteration, counting both the first and later words in repeating and poetically linked sets. In English the value is $84 \%$. In Romanian, it is $79 \%$ (SD $=$ $17 \%$; for the more common rhymes, $75 \%, S D=17 \%$; for the less common rhymes, $83 \%, S D=17 \%$ ). Thus, for each poetic device considered separately and for all poetic devices considered together, there is a marked similarity in structure between the English and the Romanian rhymes. Moreover, the common and rare rhymes do not differ greatly, supporting the idea that their similarities do not hold just for the more popular rhymes, but rather for the genre as a whole.

\section{DISCUSSION}

Counting-out rhymes offer a way of studying verbatim memory in children under naturalistic conditions. Children preserve these rhymes in nearly verbatim fashion because the rhymes must not change if they are to serve their purpose of choosing a child in a fair fashion. Moreover, the rhymes are not preserved in written form, so their stability relies on memory. The Romanian collection analyzed here provides a test of the multiple constraints claimed to be working in English. The corpus shows no overlap in rhymes with English, and because the sample was not examined, or even considered, before the analysis of the English sample was complete, it provides a clear test of the claims made there. The results are similar to those for the English rhymes. Even the form of the multiple constraints are similar to those of English. Romanian children make use of a genre, or schema, that includes, at least, repetition, rhyme, alliteration, a default of four lines, inclusion of nonsense words for either the whole rhyme or a whole line, end-rhyme schemes in couplet form, and a coherent meaning (if the rhyme is not composed of nonsense words).

Children, who are typically not the best list learners in the laboratory, recall counting-out rhymes well in both English and Romanian. The Romanian rhymes collected here had apparently spread over a large city with little variability. If our informal sampling of adults is an indication, these rhymes have remained stable for some time, just like English rhymes. The Romanian children were able to preserve almost exact wording. There is variability within the individual rhymes collected, but the variability exists within the forms of organization observed across rhymes. Moreover, the structure of the rare rhymes, most of which were collected from only one child, followed the pattern of the common rhymes. The rule-bound nature of both the changes within rhymes and the extension to rare rhymes suggests that the nearly verbatim recall is not accomplished in a rote fashion without regard for the structure of the genre. Rather, it appears that recall is schema driven by schema that have enough forms of organization to preserve the exact wording by limiting and providing multiple cuing for word choice.

\section{REFERENCES}

Abrahams, R. D., \& Rankın, L. (EDS.) (1980). Counting-out rhymes: A dictionary. Austin: University of Texas Press.

AllPORT, G. W., \& POSTMAN, L. (1947). The psychology of rumor. New York: Holt.

BARTLETT, F. C. (1932). Remembering: A study in experimental and social psychology. London: Cambridge University Press.

BuRLING, R. (1966). The metrics of children's verse: A cross-linguistic study. American Anthropologist, 68, 1418-1441.

GoldSTEIN, K. S. (1971). Strategy in counting-out: An ethnographic folklore field study. In E. M. Avedon \& B. Sutton-Smith (Eds.), The study of games (pp. 167-178). New York: Wiley.

HeRrNSTEIN SMith, B. (1968). Poetic closure: A study of how poems end. Chicago: University of Chicago Press.

JAKoBSON, R. (1960). Closing statement: Linguistics and poetics. In T. A. Sebeok (Ed.), Style in language (pp. 350-377). Cambridge, MA: MIT Press

Kelly, M. H., \& RubiN, D. C. (1988). Natural rhythmic patterns in English verse: Evidence from child counting-out rhymes. Journal of Memory \& Language, 27, 718-740.

LoRD, A. B. (1960). The singer of tales. Cambridge, MA: Harvard University Press.

Rubin, D. C. (1995). Memory in oral traditions: The cognitive psychology of epic, ballads, and counting-out rhymes. New York: Oxford University Press.

Rubin, D. C., \& WALlace, W. T. (1989). Rhyme and reason: Analyses of dual cues. Journal of Experimental Psychology: Learning. Memory, \& Cognition, 15, 698-709.

Skinner, B. F. (1939). The alliteration in Shakespeare's sonnets: A study in literary behavior. Psychological Record, 3, 186-192.

SKINNER, B. F. (1942). A quantitative estimate of certain types of soundpatterning in poetry. American Journal of Psychology, 30, 64-79.

(Manuscript received March 6, 1997; revision accepted for publication April 8, 1997.) 